\title{
Nutritional risk and gastrointestinal dysautonomia symptoms in Parkinson's disease outpatients hospitalised on a scheduled basis
}

\author{
Michela Barichella ${ }^{1}$, Emanuele Cereda ${ }^{2 *}$, Carmen Madio ${ }^{1}$, Laura Iorio ${ }^{1}$, Chiara Pusani ${ }^{1}$, \\ Raffaella Cancello ${ }^{1}$, Riccardo Caccialanza ${ }^{2}$, Gianni Pezzoli ${ }^{1}$ and Erica Cassani ${ }^{1}$ \\ ${ }^{1}$ Parkinson Institute, Istituti Clinici di Perfezionamento (ICP), via Bignami 1, 20126 Milan, Italy \\ ${ }^{2}$ Nutrition and Dietetics Service, Fondazione IRCCS Policlinico San Matteo, Viale Golgi 19, 27100 Pavia, Italy
}

(Submitted 18 May 2012 - Final revision received 20 September 2012 - Accepted 20 September 2012 - First published online 11 December 2012)

\section{Abstract}

Dysautonomia symptoms of nutritional interest may often occur in Parkinson's disease (PD), but the role played in affecting the risk of malnutrition still needs to be clarified. A total of 208 consecutive PD outpatients hospitalised on a scheduled basis were assessed for nutritional risk by the Malnutrition Universal Screening Tool. Presence of dysautonomia symptoms (dysphagia, sialorrhoea and constipation) was investigated using clinical rating scales. In our population, prevalence of nutritional risk was $17 \cdot 2$ (95\% CI $12 \cdot 1,24 \cdot 0) \%$ and relied mainly on unintentional weight loss. Sialorrhoea, dysphagia, dysphagia to liquids and constipation were observed in $10 \cdot 6,11 \cdot 0,14 \cdot 4$ and $59.6 \%$ of the patients, respectively. Nutritional risk was independently associated with the number of dysautonomia symptoms (OR 1.39 (95\% CI 1.00, 1.96); $P=0.048$ ) but not with single symptoms. An independent association was also found with the severity of motor symptoms (Hoehn-Yahr stage, OR 1.48 (95\% CI 1.00, 2.55); $P=0.049)$ and levodopa dose (OR 1.16 (95\% CI 1.04, 1.31) mg/kg per $\mathrm{d} ; P=0.009)$. Nutritional risk in PD outpatients appears to depend mainly on dysautonomic syndrome, disease severity and levodopa dosage. Implications for outcome deserve further investigation. The assessment of nutritional status and of gastrointestinal dysautonomia symptoms should be part of the routine work-up of a PD patient.

Key words: Parkinson's disease: Nutritional risk: Outpatients: Dysphagia: Sialorrhoea: Constipation

Disease-related malnutrition is one of the most, or even the most, frequent comorbidity in any healthcare setting and has relevant negative consequences on the patient's outcome ${ }^{(1-3)}$. Although the prevalence of overweight/obesity has been reported to be about twice as high as in the general population, nutritional risk and malnutrition may also occur in Parkinson's disease (PD), particularly in the advanced stages of the disease ${ }^{(4,5)}$. The pathogenesis of weight loss (WL) and/or low body weight in PD has not been elucidated, but the main causes appear to be reduced energy intake, due to several neurological, social and psychological factors, and increased energy expenditure secondary to dyskinesias ${ }^{(4,6,7)}$. Despite being mainly a neurodegenerative motor disorder, $\mathrm{PD}$ is frequently characterised by a number of gastrointestinal dysautonomia symptoms of nutritional interest, such as dysphagia, sialorrhoea and constipation, which in turn could result in an impairment of nutritional status through the modification of eating behaviours and energy balance. A Movement Disorders Society-commissioned task force has recently suggested that clinical rating scales should be used to screen for these complications ${ }^{(8)}$. An overview of prevalence data on malnutrition in PD has recently been provided $^{(9)}$, but multivariate evaluations of dysautonomia symptoms and other features of PD, with an impact on nutritional risk, are limited ${ }^{(10)}$. With this background, we designed the present study to investigate the prevalence of nutritional risk in PD and to assess the relationship between nutritional risk and PD features, including dysautonomia symptoms, as assessed by the available clinical rating scales.

\section{Materials and methods}

\section{Study design}

The study was conducted according to the guidelines laid down in the Declaration of Helsinki, and all the procedures involving human subjects were approved by the ethics committee of our institute (Istituti Clinici di Perfezionamento, Milan). Written informed consent was obtained from all patients.

We designed a prospective single-centre cohort study of all PD patients hospitalised (mean length of hospital stay: $4 \mathrm{~d}$ ) on a scheduled basis from January 2011 to October 2011 in the ward of the Parkinson Institute (Istituti Clinici di Perfezionamento

Abbreviations: MUST, Malnutrition Universal Screening Tool; PD, Parkinson's disease; WL, weight loss.

*Corresponding author: E. Cereda, fax +39 382 502801, email e.cereda@smatteo.pv.it 
Hospital, Milano). These included new patients seen at the outpatients' clinic and admitted for diagnosis confirmation and setting of drug treatment, as well as those for whom PD diagnosis had been already made. In the latter case, according to our followup protocols, PD patients are periodically hospitalised (every 2.53 years) for the re-evaluation of pharmacological treatment and the eventual execution of neuroimaging procedures.

A cross-sectional analysis of baseline data was the objective of the present study.

\section{Subject inclusion and assessment}

All patients admitted to the Institute were potentially eligible for inclusion in the study, unless they had not given their informed consent to participate in writing.

All the subjects were assessed for demographic information, PD, anthropometry, biochemistry, nutritional risk and gastrointestional dysautonomia symptons, as described.

Demographic information. Age and sex were noted.

Information on Parkinson's disease. Anti-Parkinson medications, duration of PD and its clinical rating by the Hoehn and Yahr scale (a commonly used system for describing how the symptoms of PD progress) ${ }^{(11)}$ and the unified Parkinson's disease rating scale ${ }^{(12)}$ were used. The unified Parkinson's disease rating scale is made up of several questions (answered by direct interviewing and clinical observation) grouped in four sections and addressing the following areas: part I, mentation, behaviour and mood; part II, self-evaluation of the activities of daily life (including speech, swallowing, handwriting, dressing, hygiene, falling, salivation, turning in bed, walking, cutting food, freezing when walking, tremor and sensory complaints); part III, clinician-scored motor evaluation; and part IV, complications of therapy. In regard to this scale, attention was focused on the scores of parts II and III.

Anthropometry. Weight (to the nearest $0 \cdot 1 \mathrm{~kg}$ ), standing height (to the nearest $\mathrm{cm}$ ), BMI (calculated as the ratio between weight $(\mathrm{kg})$ and height $(\mathrm{m})$ squared), mid upperarm circumference $(\mathrm{cm})$, triceps skinfold $(\mathrm{mm})$ and arm muscle area were measured. In the case of abnormal spinal curvature or evident camptocormia, the use of standing height was replaced by that of estimated height from kneeheel length. All measurements were performed according to standard procedures ${ }^{(13-16)}$. The mean of three measurements was considered in the analyses. Moreover, self-reported information on usual body weight was collected in order to assess the history of WL in the last 3-6 months.

Biochemistry. Venous blood samples were drawn after $8-12 \mathrm{~h}$ of fasting for the determination of serum albumin and transferrin. The following threshold values were considered indicative of an impairment in nutritional status: albumin $<35 \mathrm{~g} / \mathrm{l}$ and transferrin $<2000 \mathrm{mg} / \mathrm{l}^{(17)}$.

Nutritional risk. Nutritional screening was conducted through the Malnutrition Universal Screening Tool (MUST) ${ }^{(18)}$. We used this tool because, after being initially developed for use in the community, it appears to be the most popular for hospitalised patients worldwide and is recommended by the European Society of Clinical Nutrition and Metabolism due to its high degree of reliability (low inter-observer variation) and association with outcome ${ }^{(19,20)}$. The MUST is based on three clinical parameters (BMI, WL and metabolic stress due to acute disease) that have been associated with poor outcome. Each parameter is rated as 0,1 or 2 as follows: $\mathrm{BMI}>20 \mathrm{~kg} / \mathrm{m}^{2}=0$, $18.5-20.0 \mathrm{~kg} / \mathrm{m}^{2}=1$ and $<18.5 \mathrm{~kg} / \mathrm{m}^{2}=2 ; \mathrm{WL}<5 \%=0$, WL $5-10 \%=1$ and $\mathrm{WL}>10 \%=2$; acute disease: absent $=0$ and present $=2$. Accordingly, the total score (sum of the sub-scores) enables evaluation of the overall risk of malnutrition as follows: $0=$ low, $1=$ medium and $2=$ high.

Gastrointestinal dysautonomia symptoms of nutritional interest. The presence of dysphagia was assessed through the administration of the swallowing disturbance questionnaire ${ }^{(8,21)}$. The scale includes fourteen items, each with a score ranging from 0 to 3 , except one question with a score ranging from 0.5 to 2.5 . It results in a total score ranging from 0.5 to 44.5. A cut-off score $\geq 11$ has been suggested for the diagnosis of dysphagia needing treatment. However, a score $>0.5$ already means that the patients experience some degree of difficulty in swallowing. One of the questions of the scale regards dysphagia to liquids, with a score ranging from 0 (absence of dysphagia to liquids) to 3 (severe dysphagia to liquids); a score $\geq 2$ has been arbitrarily considered as threatening. The sialorrhoea clinical scale for $\mathrm{PD}^{(8,22)}$ was used for the evaluation of sialorrhoea. The scale consists of seven questions, each with a score ranging from 0 to 3 , resulting in a total score of $0-21$. A cut-off score $>11$ has been suggested for the diagnosis of sialorrhoea needing treatment; however, a score higher than 0 already means that the patient is not able to control salivation normally. Finally, Rome III criteria (constipation module) were used for the assessment of the presence of chronic constipation. According to these criteria, patients are considered to have functional constipation if they score $\geq 2$ points answering the questionnaire ${ }^{(23)}$. At present, no officially recommended assessment scales exist for PD patients, but this tool is commonly used in gastroenterology and has recently been used in this patient population ${ }^{(24)}$.

\section{Statistical analysis}

The data of the patients were used in an anonymous format with a progressive number and collected in a password-protected database. All statistical analyses were carried out using the software MEDCALC ${ }^{\circledR}$ for Windows, version 11.3.0.0 (MedCalc Software). The prevalence of malnutrition risk was computed together with its exact $95 \%$ binomial CI (95\% CI). Continuous variables were reported as mean and standard deviation or median and interquartile range (25th-75th percentile) and categorical variables as counts and percentages. Group comparisons were performed using Fisher's exact test (categorical variables) and Student's $t$ test or the Mann-Whitney $U$ test (continuous variables) when appropriate, according to normal distribution. Afterwards, multiple logistic regression analysis of non-collinear variables was performed to investigate the parameters independently associated with nutritional risk according to the MUST (score $\geq 1$ ). In these models, we decided to include only variables having a $P<0 \cdot 25$ at univariate analyses. Accordingly, data were reported as OR and their respective $95 \%$ CI. All statistical analyses were performed by setting the level of significance at a two-tailed $P<0 \cdot 05$. 


\section{Results}

\section{General features}

From January 2011 to October 2011, 208 PD patients (32.2\% females) were evaluated consecutively. Most of them were taking levodopa $(89 \cdot 3 \%)$, either alone $(33.1 \%)$ or in combination with other therapies. According to WHO criteria ${ }^{(13)}$, the distribution of patients among nutritional status categories was as follows: underweight (BMI $<18.5 \mathrm{~kg} / \mathrm{m}^{2}$ ), $1 \%$; normal weight (BMI 18.5-24.9 kg/m²), 33.0\%; overweight (BMI $25-29 \cdot 9 \mathrm{~kg} / \mathrm{m}^{2}$ ), $46 \cdot 4 \%$; and obesity (BMI $\geq 30 \mathrm{~kg} / \mathrm{m}^{2}$ ), $19 \cdot 6 \%$.

\section{Nutritional risk by Malnutrition Universal Screening Tool and related features}

Nutritional risk (MUST score $\geq 1$ ) was observed in thirty-six patients, with a prevalence of $17 \cdot 2$ (95\% CI $12 \cdot 1,24 \cdot 0) \%$ Severe nutritional risk (MUST score $\geq 2$ ) was recorded in ten

Table 1. Demographic and clinical features of the study population by nutritional risk (Malnutrition Universal Screening Tool Score $\geq 1$ ) (Mean values and standard deviations; number of counts and percentages)

\begin{tabular}{|c|c|c|c|c|c|c|c|}
\hline \multirow[b]{2}{*}{ Feature } & \multicolumn{2}{|c|}{$\begin{array}{l}\text { Overall study } \\
\text { sample }(n 208)\end{array}$} & \multicolumn{2}{|c|}{$\begin{array}{l}\text { Nutritional risk } \\
\qquad(n 36)\end{array}$} & \multicolumn{2}{|c|}{$\begin{array}{c}\text { No nutritional risk } \\
(n \text { 172) }\end{array}$} & \multirow[b]{2}{*}{$P \dagger$} \\
\hline & $n$ & $\%^{*}$ & $n$ & $\%^{*}$ & $n$ & $\%^{*}$ & \\
\hline Sex & & & & & & & 0.695 \\
\hline Male & 141 & $67 \cdot 8$ & 23 & $63 \cdot 8$ & 118 & $68 \cdot 6$ & \\
\hline Age (years) & & & & & & & 0.779 \\
\hline Mean & \multicolumn{2}{|c|}{$67 \cdot 8$} & \multicolumn{2}{|c|}{$67 \cdot 3$} & \multicolumn{2}{|c|}{$67 \cdot 8$} & \\
\hline SD & \multicolumn{2}{|c|}{$9 \cdot 2$} & \multicolumn{2}{|c|}{$9 \cdot 2$} & \multicolumn{2}{|c|}{$9 \cdot 3$} & \\
\hline Disease duration (years) & & & & & & & 0.322 \\
\hline Mean & \multicolumn{2}{|c|}{$8 \cdot 8$} & \multicolumn{2}{|c|}{$9 \cdot 8$} & \multicolumn{2}{|c|}{8.6} & \\
\hline SD & \multicolumn{2}{|c|}{$6 \cdot 2$} & \multicolumn{2}{|c|}{5.7} & \multicolumn{2}{|c|}{$6 \cdot 3$} & \\
\hline \multicolumn{8}{|l|}{ UPDRS score } \\
\hline Part II & & & & & & & 0.779 \\
\hline Mean & \multicolumn{2}{|c|}{$13 \cdot 7$} & \multicolumn{2}{|c|}{$13 \cdot 9$} & \multicolumn{2}{|c|}{$13 \cdot 4$} & \\
\hline SD & & & & & & & \\
\hline Part III & & & & & & & 0.756 \\
\hline Mean & & & & & & & \\
\hline SD & & & & & & & \\
\hline Hoehn-Yahr stage & & & & & & & 0.015 \\
\hline Stage I & 14 & $6 \cdot 7$ & 1 & $2 \cdot 8$ & 13 & $7 \cdot 6$ & \\
\hline Stage II & 137 & 65.9 & 18 & $50 \cdot 0$ & 119 & $69 \cdot 2$ & \\
\hline Stage III & 38 & $18 \cdot 3$ & 13 & $36 \cdot 1$ & 25 & 14.5 & \\
\hline Stage IV & 19 & $9 \cdot 1$ & 4 & $11 \cdot 1$ & 15 & $8 \cdot 7$ & \\
\hline Levodopa (mg/d) & & & & & & & 0.133 \\
\hline Mean & & & & & & & \\
\hline SD & & & & & & & \\
\hline Levodopa (mg/kg per d) & & & & & & & $<0.001$ \\
\hline Mean & & & & & & & \\
\hline SD & & & & & & & \\
\hline BMI $\left(\mathrm{kg} / \mathrm{m}^{2}\right)$ & & & & & & & $<0.001$ \\
\hline Mean & & & & & & & \\
\hline SD & & & & & & & \\
\hline$\leq 20 \mathrm{~kg} / \mathrm{m}^{2}$ & 7 & 3.6 & 7 & $19 \cdot 4$ & & & $<0.001$ \\
\hline$<18.5 \mathrm{~kg} / \mathrm{m}^{2}$ & 1 & 0.5 & 1 & $2 \cdot 8$ & & & 0.173 \\
\hline Weight loss & & & & & & & $<0.001$ \\
\hline$\geq 5 \%$ & 35 & $16 \cdot 8$ & 35 & $97 \cdot 2$ & & & \\
\hline$>10 \%$ & 7 & 3.6 & 7 & 19.4 & & & $<0.001$ \\
\hline Presence of acute disease & 0 & & 0 & & & & 1.000 \\
\hline Albumin $(g / l)$ & & & & & & & 0.510 \\
\hline Mean & & & & & & & \\
\hline SD & & & & & & & \\
\hline$<35 \mathrm{~g} / \mathrm{l}$ & 22 & $10 \cdot 6$ & 5 & 13.9 & 17 & $9 \cdot 9$ & 0.550 \\
\hline Transferrin (mg/l) & & & & & & & 0.598 \\
\hline Mean & & & & & & & \\
\hline SD & & & & & & & \\
\hline$<200 \mathrm{mg} / \mathrm{l}$ & 25 & 120 & 4 & 111 & 21 & 122 & 1.000 \\
\hline SCS-PD score > 11 & 22 & $10 \cdot 6$ & 8 & $22 \cdot 2$ & 14 & $8 \cdot 1$ & 0.019 \\
\hline SQD score $>11$ & 23 & 11 & 6 & $16 \cdot 7$ & 17 & 9.9 & 0.246 \\
\hline SQD for liquids score $\geq 2$ & 30 & 14.4 & 8 & $22 \cdot 2$ & 22 & $12 \cdot 8$ & 0.189 \\
\hline Constipation & 124 & $59 \cdot 6$ & 25 & $69 \cdot 4$ & 99 & $57 \cdot 6$ & 0.198 \\
\hline
\end{tabular}

UPDRS, unified Parkinson's disease rating scale (part II, activity of daily living; part III, motor examination); SCS-PD, sialorrhoea clinical scale for Parkinson's disease; SQD score, swallowing disturbance questionnaire.

* Percentages are calculated within single groups.

† Variables were compared between groups with Student's $t$ test, the Mann-Whitney $U$ test or Fisher's exact test as appropriate. 
patients $(5 \%)$ and relied mainly on WL $(>10 \%$ in seven patients). The clinical features of the population by nutritional risk are summarised in Table 1. Patients at nutritional risk presented with lower BMI, reported WL more frequently, but none reported the presence of acute disease. Moreover, they were more likely to have more severe symptoms, as assessed by the Hoehn-Yahr staging system, to experience sialorrhoea and to require higher levodopa dosages than those with a normal nutritional status.

\section{Gastrointestinal dysautonomia symptoms and related features}

In the overall population, the frequency of sialorrhoea, dysphagia, dysphagia to liquids and constipation was 10.6, 11.0, 14.4 and $59.6 \%$, respectively. However, the proportion of patients reporting at least one symptom indicating difficulties in swallowing and some degree of sialorrhoea was 58.2 and $55.8 \%$, respectively. The clinical features of the population are presented by complication in Table 2 . With the exception of constipation, dysautonomia symptoms were significantly associated with each other and with more severe symptoms, either assessed by the unified Parkinson's disease rating scale or the Hoehn-Yahr staging system. Patients with sialorrhoea were also characterised by longer disease duration. Higher levodopa dosages were also observed in patients with sialorrhoea and dysphagia.

\section{Predictors of nutritional risk}

Finally, we evaluated the independent predictors of nutritional risk by logistic regression analyses (Table 3). In multivariable

Table 2. Clinical features of the study population by presence of gastrointestinal dysautonomia symptoms

(Mean values and standard deviations; counts and percentages)

\begin{tabular}{|c|c|c|c|c|c|c|c|c|c|c|c|c|c|c|c|c|}
\hline \multirow[b]{4}{*}{ Feature* } & \multirow{2}{*}{\multicolumn{4}{|c|}{ Sialorrhoea }} & \multirow{2}{*}{\multicolumn{8}{|c|}{ Swallowing disturbances }} & \multirow{2}{*}{\multicolumn{4}{|c|}{$\begin{array}{c}\text { Constipation } \\
\text { Rome III criteria }\end{array}$}} \\
\hline & & & & & & & & & & & & & & & & \\
\hline & \multicolumn{2}{|c|}{$\begin{array}{l}\text { SCS-PD } \\
\text { score } \leq 11 \\
(n 186)\end{array}$} & \multicolumn{2}{|c|}{$\begin{array}{l}\text { SCS-PD } \\
\text { score }>11 \\
\quad(n 22)\end{array}$} & \multicolumn{2}{|c|}{$\begin{array}{l}\text { Total SQD } \\
\text { score } \leq 11 \\
\quad(n 185)\end{array}$} & \multicolumn{2}{|c|}{$\begin{array}{l}\text { Total SQD } \\
\text { score }>11 \\
\quad(n 23)\end{array}$} & \multicolumn{2}{|c|}{$\begin{array}{l}\text { SQD score } \\
\text { for liquids } \\
<2(n 178)\end{array}$} & \multicolumn{2}{|c|}{$\begin{array}{l}\text { SQD score } \\
\text { for liquids } \\
\geq 2(n 30)\end{array}$} & \multicolumn{2}{|c|}{ No $(n 84)$} & \multicolumn{2}{|c|}{ Yes $(n 124)$} \\
\hline & $n$ & $\% †$ & $n$ & $\% \dagger$ & $n$ & $\% \dagger$ & $n$ & $\% \dagger$ & $n$ & $\% \dagger$ & $n$ & $\% \dagger$ & $n$ & $\% \dagger$ & $n$ & $\% \dagger$ \\
\hline \multicolumn{17}{|l|}{ Age (years) } \\
\hline Mean & \multirow{2}{*}{\multicolumn{2}{|c|}{$\begin{array}{c}67.4 \\
9.4\end{array}$}} & \multicolumn{2}{|c|}{$70 \cdot 5$} & \multicolumn{2}{|c|}{$67 \cdot 6$} & \multicolumn{2}{|c|}{$69 \cdot 2$} & \multicolumn{2}{|c|}{67.9} & \multicolumn{2}{|r|}{$66 \cdot 9$} & \multicolumn{2}{|c|}{65.5} & \multicolumn{2}{|c|}{69.4} \\
\hline SD & & & \multicolumn{2}{|c|}{$7 \cdot 2$} & & 2 & & .7 & & 3 & & 9.0 & & 0.4 & & $0 \ddagger$ \\
\hline Disease duration (years) & \multicolumn{2}{|c|}{$9 \cdot 4$} & & & & & & & & & & & & & & \\
\hline Mean & & & & $3 \cdot 6$ & & 7 & & 6 & & 6 & & $10 \cdot 4$ & & 2 & & .2 \\
\hline SD & & & & $4 \ddagger$ & & 2 & & .8 & & 9 & & $7 \cdot 4$ & & 5 & & 0 \\
\hline UPDRS score & & & & & & & & & & & & & & & & \\
\hline Part II & & & & & & & & & & & & & & & & \\
\hline Mean & & & & $8 \cdot 8$ & & 8 & & 0.2 & & .9 & & $17 \cdot 9$ & & $4 \cdot 1$ & & 3.4 \\
\hline SD & & & & $3 \ddagger$ & & 9 & & $9 \S$ & & 7 & & $10 \cdot 0 \|$ & & .7 & & 5 \\
\hline Part III & & & & & & & & & & & & & & & & \\
\hline Mean & & & & 0.3 & & .5 & & 0.2 & & 0 & & $29 \cdot 7$ & & 3.5 & & 3.0 \\
\hline SD & & & & .59 & & 8 & & $4 \ddagger$ & & 6 & & $12 \cdot 3 \S$ & & $1 \cdot 2$ & & .4 \\
\hline Hoehn-Yahr stage & & & & & & & & & & & & & & & & \\
\hline Stage I & 14 & 7.5 & 0 & & 14 & $7 \cdot 6$ & 0 0ा & & 14 & 7.9 & $0 \ddagger$ & & 8 & 9.5 & 6 & 4.9 \\
\hline Stage II & 124 & $66 \cdot 7$ & 13 & $59 \cdot 1$ & 127 & $68 \cdot 6$ & 10 & 43.5 & 122 & 68.5 & 15 & 50 & 53 & 63.1 & 84 & $67 \cdot 7$ \\
\hline Stage III & 32 & $17 \cdot 2$ & 6 & $27 \cdot 3$ & 30 & $16 \cdot 2$ & 8 & $34 \cdot 8$ & 28 & $15 \cdot 7$ & 10 & 33.4 & 16 & $19 \cdot 1$ & 22 & $17 \cdot 7$ \\
\hline Stage IV & 16 & $8 \cdot 6$ & 3 & $13 \cdot 6$ & 14 & $7 \cdot 6$ & 5 & $21 \cdot 7$ & 14 & 7.9 & 5 & $16 \cdot 6$ & 7 & $8 \cdot 3$ & 12 & $9 \cdot 7$ \\
\hline Levodopa (mg/kg per d) & & & & & & & & & & & & & & & & \\
\hline Mean & & & & 1.6 & & 4 & & 0.3 & & 4 & & $9 \cdot 2$ & & .5 & & .8 \\
\hline SD & & & & $6 \S$ & & 5 & & $7 \|$ & & 5 & & 4.9 & & 3 & & $\cdot 0$ \\
\hline BMI $\left(\mathrm{kg} / \mathrm{m}^{2}\right)$ & & & & & & & & & & & & & & & & \\
\hline Mean & & & & $5 \cdot 1$ & & 7 & & 7.6 & & 8 & & $26 \cdot 6$ & & 7.4 & & 3 \\
\hline SD & & & & $.7 \|$ & & 1 & & 1 & & 3 & & 4.0 & & .7 & & .9 \\
\hline$<20 \mathrm{~kg} / \mathrm{m}^{2}$ & 5 & $2 \cdot 7$ & 2 & $9 \cdot 1$ & 6 & $3 \cdot 2$ & 1 & $4 \cdot 3$ & 6 & 3.4 & 1 & 3.3 & 2 & $2 \cdot 4$ & 5 & $4 \cdot 0$ \\
\hline Weight loss $\geq 5 \%$ & 27 & 14.5 & 8 & $36 \cdot 4 \ddagger$ & 31 & $16 \cdot 8$ & 4 & $17 \cdot 4$ & 28 & $15 \cdot 7$ & 7 & $23 \cdot 3$ & 12 & $14 \cdot 3$ & 23 & 18.5 \\
\hline MUST score $\geq 1$ & 28 & $15 \cdot 1$ & 8 & $36 \cdot 4 \ddagger$ & 31 & $16 \cdot 8$ & 5 & $21 \cdot 7$ & 29 & $16 \cdot 3$ & 7 & $23 \cdot 3$ & 12 & $14 \cdot 3$ & 24 & $19 \cdot 4$ \\
\hline SCS-PD score > 11 & & & & - & 14 & $7 \cdot 6$ & 8 & $34.8 \S$ & 13 & $7 \cdot 3$ & 9 & $30 \S$ & 7 & $8 \cdot 3$ & 15 & $12 \cdot 1$ \\
\hline SQD score > 11 & 15 & $8 \cdot 1$ & 8 & $36.4 \S$ & & - & & - & 10 & $5 \cdot 6$ & 13 & $43.3 \S$ & 7 & $8 \cdot 3$ & 16 & 12.9 \\
\hline SQD score for liquids $\geq 2$ & 21 & $11 \cdot 3$ & 9 & $40.9 \S$ & 17 & $9 \cdot 2$ & 13 & $56.5 \S$ & & - & & - & 12 & $14 \cdot 3$ & 18 & 14.5 \\
\hline Constipation & 109 & 58.6 & 15 & $68 \cdot 2$ & 108 & $58 \cdot 4$ & 16 & 69.6 & 106 & $59 \cdot 6$ & 18 & 60 & & - & & - \\
\hline
\end{tabular}

SCS-PD, sialorrhoea clinical scale for Parkinson's disease; SQD score, swallowing disturbance questionnaire; UPDRS, unified Parkinson's disease rating scale (part II, activity of daily living; part III, motor examination); MUST, malnutrition universal screening tool.

${ }^{*}$ Continuous and categorical variables were compared between groups with Student's $t$ test, the Mann-Whitney $U$ test or Fisher's exact test as appropriate

$\dagger$ Percentages are calculated within single groups.

$\ddagger P<0.02$.

$\S P<0.001$.

$\| P<0.05$.

I $P<0.01$. 
Table 3. Associations with nutritional risk (Malnutrition Universal Screening Tool score $\geq 1$ ): logistic regression analyses of non-collinear variables (Odds ratios and $95 \%$ confidence intervals)

\begin{tabular}{|c|c|c|c|c|c|c|c|c|c|}
\hline \multirow[b]{2}{*}{ Feature } & \multicolumn{2}{|c|}{ Univariate analysis } & \multirow[b]{2}{*}{$P$} & \multicolumn{2}{|c|}{$\begin{array}{c}\text { Multivariate } \\
\text { analysis }^{*}\end{array}$} & \multirow[b]{2}{*}{$P$} & \multicolumn{2}{|c|}{$\begin{array}{c}\text { Multivariate } \\
\text { analysis }\end{array}$} & \multirow[b]{2}{*}{$P$} \\
\hline & OR & $95 \% \mathrm{Cl}$ & & OR & $95 \% \mathrm{Cl}$ & & OR & $95 \% \mathrm{Cl}$ & \\
\hline Age (years) & 0.99 & $0.96-10.03$ & 0.777 & & & & & & \\
\hline \multicolumn{10}{|l|}{ Sex } \\
\hline Male & 0.62 & $0.29-1.29$ & 0.199 & 0.50 & $0.20-1.24$ & 0.137 & 0.63 & $0.26-1.51$ & 0.299 \\
\hline \multirow{2}{*}{\multicolumn{10}{|c|}{ UPDRS score }} \\
\hline & & & & & & & & & \\
\hline Part II & 1.01 & $0.95-1.08$ & 0.777 & & & & & & \\
\hline Part III & 1.01 & $0.97-1.04$ & 0.714 & & & & & & \\
\hline Hoehn and Yahr stage & 1.72 & $1.08-2.73$ & 0.021 & 1.65 & $1 \cdot 01-2 \cdot 77$ & 0.042 & 1.48 & $1.00-2.55$ & 0.049 \\
\hline Levodopa dose (mg/kg per d) & $1 \cdot 19$ & $1.07-1.32$ & 0.002 & $1 \cdot 16$ & $1.03-1.30$ & 0.012 & $1 \cdot 16$ & $1.04-1.31$ & 0.009 \\
\hline SCS-PD score $>11$ & $3 \cdot 18$ & $1.22-8.29$ & 0.018 & 2.47 & $0.63-9.72$ & 0.196 & & - & \\
\hline SQD score $>11$ & 1.45 & $0.50-4.23$ & 0.494 & & & & & & \\
\hline Constipation & 1.43 & $0.67-3.06$ & 0.350 & & & & & & \\
\hline Dysautonomia symptoms $\dagger$ & 1.45 & $1 \cdot 00-2 \cdot 11$ & 0.049 & & - & 1.39 & $1.00-1.96$ & & 0.048 \\
\hline
\end{tabular}

models, nutritional risk was significantly associated with more severe disease, as assessed according to Hoehn-Yahr stage, levodopa dosage and the number of non-motor complications. No single dysautonomic symptom was independently associated with nutritional risk.

\section{Discussion}

The present study showed that the prevalence of nutritional risk in PD patients hospitalised on a scheduled basis is about half of that of the general hospital population. The present data are in agreement with those of previous studies investigating the prevalence of nutritional derangements by means of multidimensional screening tools ${ }^{(5,10,25)}$. In respect to this issue, the present study emphasises the importance of using these assessment tools, because the large variation in prevalence across previously published studies appears to be due to differences in nutritional assessment methods and in the definition of malnutrition ${ }^{(9)}$. Several reports, including the present, have reported that the prevalence of overweight and obesity is about twice as high as in the general Italian population $^{(4,26)}$. This has been explained as a consequence of the changes in lifestyle (e.g. reduction in physical activity) and the important improvements in the therapeutic management (pharmacological and/or surgical) of the disease achieved in the last decades ${ }^{(4)}$. Accordingly, using only BMI in the nutritional screening or assessment of the PD patient is a limitation, which could lead to a significant underestimation of nutritional derangements. Also body weight excess deserves attention from a nutritional standpoint due to its association with morbidity and mortality ${ }^{(13)}$. However, PD patients appear apparently protected from CVD due to a more favourable metabolic profile, which seems to be independent of nutritional status and total and abdominal adiposity $^{(4,26,27)}$.

The key feature of nutritional risk in the present study was WL, a finding in agreement with a previous report ${ }^{(4,28)}$.
The present prevalence data have important implications for clinical practice, because the risk of malnutrition in elderly patients has been related to the setting and the level of assistance, with significantly lower rates being reported in outpatient populations ${ }^{(3)}$. However, the lower prevalence of nutritional risk, compared with the general hospital population $^{(1,2,18-20)}$, reasonably reflects the pathophysiology of nutritional risk. The present study population included outpatients who were not hospitalised for acute conditions frequently characterised by an inflammatory background. This is supported also by other data because biochemical protein markers of nutritional status associated with inflammation ${ }^{(17)}$, particularly albumin, were unrelated to MUST score. Along with this, it has been shown that the reduction in body weight in PD patients occurs mainly at the expense of fat mass rather than lean body mass ${ }^{(4,28)}$, a body compartment that is generally affected by inflammatory diseases ${ }^{(1)}$. In respect with the setting of provenience, the present study agrees with that by Jaafar et al. ${ }^{(25)}$. On the other hand, although the MUST was primarily developed for the community setting and its use in hospitals has been supported by several studies ${ }^{(1,18-20)}$, the present observations suggest raising questions about the appropriateness of this tool in PD outpatients. Given the prevalence of overweight/obesity in PD patients and the prevalent absence of acute disease, it is possible that the MUST may have not correctly identified all those at risk. In hospital inpatients, prevalence of nutritional risk by MUST is reported to be up to $60 \%$ and in outpatients up to $30 \%{ }^{(18)}$. All these aspects are of importance because screening represents the first step in nutritional assessment and further investigation is warranted when risk is detected.

Previous studies have attempted to explain the causes of WL in PD patients, and available evidence suggests that both changes in energy intake and expenditure contribute to this process $^{(4)}$. Increased energy requirements have been associated with motor function deterioration, particularly with muscle rigidity and levodopa-induced dyskinesia ${ }^{(4,6)}$. 
Moreover, a stimulating effect of levodopa on energy metabolism has been proposed ${ }^{(29)}$. The present results are consistent with previous findings, as levodopa doses and severity of disease were independently associated with nutritional risk, thus supporting the belief that malnutrition is intrinsically related to the course of the disease and levodopa-related complications ${ }^{(4,6)}$. Akinetic state, as reflected by more severe disease, could also result in impaired food intake due to poor hand-mouth coordination. It has been suggested that the reduction in energy intake may depend on other factors, such as reduced food interest secondary to hyposmia, psychosocial factors (e.g. mood disorders or difficulties in preparing meals secondary to disability), as well as gastrointestinal dysfunction (e.g. swallowing disturbances $)^{(4,7,29)}$. Unfortunately, in the present study, we did not assess energy intake due to technical difficulties. Patients admitted to our Institute came from the whole Italian country and quantitative dietary assessments by means of food diaries could not be planned, while the use of the 24-h dietary recall may result in over-or underestimation of daily energy intake. However, our research group has previously demonstrated that nutritional status deterioration by the mini nutritional assessment was mainly related to those questions focusing on dietary habits ${ }^{(5)}$. On the other hand, we found that swallowing disturbances, which are generally associated with reduced food intake, were unrelated to nutritional risk. Protein redistribution diets could contribute to WL in PD patients ${ }^{(30)}$. However, although neurologists should recommend the adherence to this dietetic regimen on an individualised basis to those experiencing motor fluctuations, many PD patients have a dietary pattern similar to that of the general population ${ }^{(31)}$

In contrast with previous evidence collected in patients with other diseases, in the present survey, nutritional risk was not associated with reduced activities of daily living ${ }^{(3)}$. Moreover, only the number of dysautonomia symptoms was significantly correlated with nutritional risk, whilst no independent effect for single symptoms was demonstrated. Although it can be argued that difficulty in swallowing solid food due to oropharyngeal dysfunction may increase WL, mainly in the advanced rather than in early stages of $\mathrm{PD}^{(4,7)}$, in the present study, neither swallowing difficulties nor nutritional risk were related to duration of PD.

There is only one report, as far as we are aware, investigating the association between malnutrition and gastrointestinal dysautonomia symptoms other than dysphagia. Wang et $a l .{ }^{(10)}$ found that constipation predicted nutritional risk. Someone could argue that the lack of association with single non-motor complications depends on the method used for the assessment. Indeed, clinical rating scales are simple instruments to be used for screening purposes, leaving the clinician the possibility to continue the diagnostic work-up with more complex and expensive assessments, should complications be suspected. Nonetheless, the prevalence of dysautonomic symptoms detected in the present study using clinical rating scales was similar to the figures previously reported in the literature (dysphagia, 30-80\%; sialorrhoea, 70-75\%; and constipation, $60 \%)^{(4,24-32)}$ and symptoms were correlated to each other. Moreover, taken together, these symptoms were associated with nutritional risk, to which they probably contribute to different extents. Sialorrhoea consists of the alteration of salivation control associated with unpleasant drooling. In PD patients, it is more likely to be secondary to swallowing abnormalities than to excessive salivary production $^{(8,32)}$, and the association found with other symptoms of autonomic nervous system dysfunction supports this hypothesis. Sialorrhoea may be responsible for discomfort or social embarrassment, thus inducing the patient to change dietary habits, which, in turn, could be also negatively affected by swallowing difficulties or abdominal distension due to constipation.

A potential inclusion bias should be taken into account. Patients with severe disability and/or cognitive impairment were more likely to be excluded. Accordingly, the prevalence of nutritional risk, as well as the contribution of these conditions in the overall population of PD patients, may have been partly underestimated. However, our data are likely to be representative of the PD outpatient population, because patients with severe disability and/or cognitive impairment are frequently admitted to long-term care facilities.

Finally, depression was not included among the assessments. This limitation is also recognised because Wang et $a l^{(10)}$ have recently demonstrated a significant association with nutritional risk.

In conclusion, the present paper shows that, in PD patients, the nutritional domain should be object of periodic evaluations during the course of the disease. In respect of this, attention should be focused on several factors and through a multidisciplinary approach because the heterogeneous changes potentially occurring seem to be of multifactorial origin. This approach could allow the introduction of effective dietary treatment promptly. Nonetheless, the use of other screening tools along with the implications of nutritional risk on patient outcome should be addressed by future studies.

\section{Acknowledgements}

The authors wish to thank Jennifer S. Hartwig, MD, for editorial assistance. All the authors certify that there are no affiliations with or involvement in any organisation or entity with a direct financial interest in the subject matter or materials discussed in the manuscript. E. Cereda has received consultancy honoraria and investigator grants from Nutricia Italia and the 'Fondazione Grigioni per il Morbo di Parkinson'. All authors significantly contributed to the work, and read and approved the final version of the manuscript. All authors, external and internal, had full access to all of the data (including statistical reports and tables) in the study and can take responsibility for the integrity of the data and the accuracy of the data analysis. In particular, contributions were as follows: M. B. contributed to the study design, data interpretation, review and critique. E. Cereda performed the data analysis, data interpretation and drafting of the manuscript. C. M., L. I. and C. P. carried out data collection. R. Cancello was involved in data collection and data interpretation. R. Caccialanza carried out data interpretation. G. P. was involved in the supervision, review and critique. Erica Cassani aided in study design, data 
collection, and drafting of the manuscript. The present study was supported by the 'Fondazione Grigioni per il Morbo di Parkinson'.

\section{References}

1. Norman K, Pichard C, Lochs H, et al. (2008) Prognostic impact of disease-related malnutrition. Clin Nutr 27, 5-15.

2. Cereda E, Lucchin L, Pedrolli C, et al. (2010) Nutritional care routines in Italy: results from the PIMAI (Project: Iatrogenic MAlnutrition in Italy) study. Eur J Clin Nutr 64, 894-898.

3. Cereda E (2012) Mini Nutritional Assessment (MNA ${ }^{\circledR}$ ). Curr Opin Clin Nutr Metab Care 15, 29-41.

4. Barichella M, Cereda E \& Pezzoli G (2009) Major nutritional issues in the management of Parkinson's disease. Mov Disord 24, 1881-1892.

5. Barichella M, Villa MC, Massarotto A, et al. (2008) Mini Nutritional Assessment in patients with Parkinson's disease: correlation between worsening of the malnutrition and increasing number of disease-years. Nutr Neurosci 11, 128-134.

6. Cereda E, Pezzoli G \& Barichella M (2010) Role of an electronic armband in motor function monitoring in patients with Parkinson's disease. Nutrition 26, 240-242.

7. Bachmann CG \& Trenkwalder C (2006) Body weight in patients with Parkinson's disease. Mov Disord 21, 1824-1830.

8. Evatt ML, Chaudhuri KR, Chou KL, et al. (2009) Dysautonomia rating scales in Parkinson's disease: sialorrhea, dysphagia, and constipation - critique and recommendations by movement disorders task force on rating scales for patients with Parkinson disease. Mov Disord 24, 635-636.

9. Sheard JM, Ash S, Silburn PA, et al. (2011) Prevalence of malnutrition in Parkinson's disease: a systematic review. Nutr Rev 69, 520-532.

10. Wang G, Wan Y, Cheng Q, et al. (2010) Malnutrition and associated factors in Chinese patients with Parkinson's disease: results from a pilot investigation. Parkinsonism Relat Disord 16, 119-123.

11. Hoehn M \& Yahr M (1967) Parkinsonism: onset, progression and mortality. Neurology 17, 427-442.

12. Fahn S, Elton RL \& UPDRS Program Members (1987) Unified Parkinson's disease rating scale. In Recent Developments in Parkinson's Disease, vol. 2, pp. 153-163, 293-304 [S Fahn, CD Marsden, M Goldstein and DB Calne, editors]. Florham Park, NJ: Macmillan Healthcare Information.

13. World Health Organization (1995) Physical status: the use and interpretation of anthropometry. Report of a WHO Expert Committee. World Health Organ Tech Rep Ser 854 , $1-452$.

14. Kuczmarski MF, Kuczmarski RJ \& Najjar M (2000) Descriptive anthropometric reference data for older Americans. $J \mathrm{Am}$ Diet Assoc 100, 59-66.

15. Frisancho AR (1981) New norms of upper limb fat and muscle areas for assessment of nutritional status. Am J Clin Nutr 34, 2540-2545.
16. Cereda E, Bertoli S, Vanotti A, et al. (2010) Estimated height from knee-height in Caucasian elderly: implications on nutritional status by Mini Nutritional Assessment. J Nutr Health Aging 14, 16-22.

17. Omran ML \& Morley JE (2000) Assessment of protein energy malnutrition in older persons, part II: laboratory evaluation. Nutrition 16, 131-140.

18. Stratton RJ, Hackston A, Longmore D, et al. (2004) Malnutrition in hospital outpatients and impatients: prevalence, concurrent validity and ease of use of the "malnutrition universal screening tool" (MUST) for adults. Br J Nutr 92, 799-798.

19. Kondrup J, Allison SP, Elia M, et al. (2003) ESPEN guidelines for nutrition screening 2002. Clin Nutr 22, 415-421.

20. Schindler K, Pernicka E, Laviano A, et al. (2010) How nutritional risk is assessed and managed in European hospitals: a survey of 21,007 patients findings from the 2007-2008 crosssectional nutritionDay survey. Clin Nutr 29, 552-559.

21. Manor Y, Giladi N, Cohen A, et al. (2007) Validation of a swallowing disturbance questionnaire for detecting dysphagia in patients with Parkinson's disease. Mov Disord 22 1917-1921.

22. Perez Lloret S, Pirán Arce G, Rossi M, et al. (2007) Validation of a new scale for the evaluation of sialorrhea in patients with Parkinson's disease. Mov Disord 22, 107-111.

23. Rome Foundation, Inc. (2012) Rome III Disorders and Criteria. http://www.romecriteria.org

24. Kaye J, Gage H, Kimber A, et al. (2006) Excess burden of constipation in Parkinson's disease: a pilot study. Mov Disord 21, 1270-1273.

25. Jaafar AF, Gray WK, Porter B, et al. (2010) A cross-sectional study of the nutritional status of community-dwelling people with idiopathic Parkinson's disease. BMC Neurol 10, 124.

26. Cereda E, Cassani E, Barichella M, et al. (2011) Anthropometric indices of fat distribution and cardiometabolic risk in Parkinson's disease. Nutr Metab Cardiovasc Dis (epublication ahead of print version 7 September 2011).

27. Cereda E, Cassani E, Barichella M, et al. (2012) Low cardiometabolic risk in Parkinson's disease is independent of nutritional status, body composition and fat distribution. Clin Nutr, 31, 699-704.

28. Chen H, Zhang SM, Hernán MA, et al. (2003) Weight loss in Parkinson's disease. Ann Neurol 53, 676-679.

29. Kashihara K (2005) Weight loss in Parkinson's disease. J Neurol 253, Suppl. 7, VII38-VII41.

30. Cereda E, Barichella M, Pedrolli C, et al. (2010) Low-protein and protein-redistribution diets for Parkinson's disease patients with motor fluctuations: a systematic review. Mov Disord 25, 2021-2034.

31. Marczewska A, De Notaris R, Sieri S, et al. (2006) Protein intake in Parkinsonian patients using the EPIC food frequency questionnaire. Mov Disord 21, 1229-1231.

32. Adler CH (2005) Nonmotor complications in Parkinson's disease. Mov Disord 20, S23-S29.

33. Pfeiffer RF (2003) Gastrointestinal dysfunction in Parkinson's disease. Lancet Neurol 2, 107-116. 